\title{
Intuitions about Penalties and Compensation in the Context of Tort Law
}

\author{
JONATHAN BARON \\ Department of Psychology, University of Pennsylvania, 3815 Walnut Street, Philadelphia, PA 19104-6196 \\ ILANA RITOV* \\ Deparment of Industrial Engineering and Management, Ben-Gurion University, P.O. Box 653, Beer Sheeva \\ 84105, Istael
}

\section{Abstract}

Students, retired judges, economists, and others made judgments of appropriate penalties and compensation for hypothetical injuries. In some scenarios, compensation was paid by the government and penalties were paid to the government, so the two could differ. Penalties were generally uninfluenced by their deterrent effect on future behavior. Penalties were greater when they were paid directly to the victim than when they were paid to the government. Compensation was affected by whether injuries were caused by people or by nature, or by acts vs. omissions. These effects are not justified according to consequentialist views of penalties and compensation. We suggest that people are overgeneralizing reasonable rules and that such overgeneralization may be involved in perverse effects of tort law.

Key words: tort law, penalties, compensations, intuitive judgments

When one person (or group) harms another, people often think that the injurer should compensate the victim. Tort law can compel compensation. Such a transaction not only compensates the victim but also punishes the injurer. When the injurer compensates the victim, as when a child is induced to give back something she has taken or when a victim sues an injurer in court, punishment and compensation are linked together. Sometimes these functions are separated. Criminals are punished whether or not their victims are compensated. Insurance (private and social) provides compensation for misfortunes regardless of whether they are caused by people or nature, and regardless of whether the insurer collects from the injurer.

In the studies described here, we sought to understand how people think about punishment and compensation in the context of hypothetical cases in which people are killed or injured by birth-control pills or vaccines. These are typical situations in which lawsuits against companies occur. Some of our cases separated punishment and compensation, so that we could learn how people think about each function alone.

*We thank David Houston, Robert Field, Rajeev Gowda, John C. Hershey, Jacqueline Meszaros, George Priest, and the anonymous reviewers for helpful suggestions, and Penny Pollister and Joanne Schwartz for research assistance. This work was supported by a grant from the National Science Foundation (SES-8809299). 
It has been argued that the tort system sometimes leads systematically to undesirable results (e.g., Huber, 1988, 1991). Rather than encouraging safety improvements or causing harmful products to be withdrawn, tort penalties have caused highly beneficial products - such as vaccines and birth-control products-to be withdrawn and have led to a reduction in research and development expenditures for similar products. For example, pertussis vaccine might cause brain damage or death in small numbers of children, although whooping cough, the disease it prevents, is far more dangerous. Production of this vaccine in the U.S. declined drastically as a result of lawsuits (David, 1986; Hinman, 1986; Huber, 1988; Inglehart, 1987), and the price increased, although the passage of a (partial) no-fault compensation law in 1986 may have reversed this trend (Hofmann, 1988). Likewise, research on new birth-control methods seems to have decreased for the same reason (Djerassi, 1989; Huber, 1988; Mastroianni, Donaldson and Kane, 1990).

Viscusi and Moore (in press) present general evidence that liability costs tend to increase research and development expenditures up to a point and then cause a decline when the costs are sufficiently high. Although it is likely that some products should be withdrawn from the market, or not developed, because their harm exceeds their benefit, the examples cited by Viscusi and Moore, as well as those just cited, suggest that many successful lawsuits do not involve such harmful products.

The motive of courts in these cases could have been to compensate victims, but U.S. society makes no comparable effort to compensate victims of natural disease for their misfortune. In this article, we suggest that undesirable results of the liability system could result in part from the intuitions of those involved in the system-judges, lawyers, plaintiffs, defendants, and juries-about what penalties ought to be assessed and what compensation ought to be paid. In particular, two basic intuitive principles may be involved: the desire for retribution against an injurer, whatever the consequences; and the dependence of compensation judgments on judgments of human responsibility, so that compensation is considered more necessary when the injury is caused by a human act. These effects could be exacerbated by the usual linkage of compensation and penalties. Use of these intuitive principles, which are not based on expected consequences, could help to produce the kinds of undesirable outcomes that have led to complaints.

Conceivably, the attempt to consider consequences directly might be self-defeating, and intuitive rules of this sort might yield better results in the long run. However, people who accept rules without understanding their consequentialist justifications can be induced to use rules that have no such justification.

\section{Consequentialist accounts of penalties and compensation}

Consequentialism justifies penalties by their deterrent function, i.e., by the fact that they provide an incentive to do something other than what was penalized. Thus, a penalty with no beneficial deterrent effect is simply an unjustified wrong against the injurer, and "two wrongs don't make a right." Even if other factors are involved in determining penalties, we might expect deterrence considerations to affect their magnitude. 
Several scholars from the "law and economics" tradition (e.g., Brown, 1973; Landes and Posner, 1987; Shavell, 1987) have argued that deterrence provides the main justification of the common law of torts. Landes and Posner (1987) argue that common law has evolved to serve this function, despite the fact that many of its precepts seem nonintuitive to laypeople and the fact that the judges who made the law did not themselves understand the full economic rationale.

Compensation can be given a consequentialist justification as a form of insurance, as when damaged property is replaced by an injurer or an insurance company (Calabresi, 1970). The loss increases the utility of money for the victim: if your car is stolen, you can use money more efficiently to achieve your goals than you could before, e.g., you can buy a new car (Calfee and Rubin, in press; Friedman, 1982; Schwartz, 1988). It is irrelevant to this justification whether an injury is brought about by a negligent act, an innocent act, an omission, or a natural misfortune. (Compensation can also be justified as an incentive for victims to sue or complain.) Critics of the U.S. legal system maintain that those who sue successfully are well compensated, while others who suffer the same injury at the hands of nature (or the hands of a "shallow pocket") are left to fend for themselves, although the insurance justification is the same in both cases.

\section{Psychological mechanisms}

We hypothesize that people make judgments of penalties and compensation on the basis of general intuitive rules, which often do produce the best consequences, but that people do not understand the consequentialist justifications of these rules (Baron, 1991, in press). As a result, people apply the rules to cases in which the justifications are absent. Previous studies (e.g., Baron and Hershey, 1988; Ritov and Baron, 1990; Spranca, Minsk, and Baron, 1991) support these general claims. Two instances of the general hypothesis are examined: 1) people will not refer to the deterrence justification of punishment judgments on other principles, such as retribution; and 2) compensation judgments will be affected by factors that affect penalties but do not affect the insurance function of compensation; these factors include the negligence of the injurer and whether the injury was caused by an act, by an omission, or by nature.

Retribution and deterrence are typically correlated. Through observation, people could come to think of punishment solely as retribution, without understanding that retribution is beneficial at least partly because of its correlation with deterrence. Their intuitive rule for the justification of punishment is, then, that it should depend on the magnitude of the harm and the intention behind it (Fincham and Jaspers, 1980), not on its deterrent effect. When the correlation between deterrence and retribution is broken, they will stick with retribution.

Other research suggests that many people do not take deterrence into account. Baron, Gowda, and Kunreuther (1993) have examined intuitions about deterrence in the context of hazardous waste, where compensation is not at issue. The subjects included 
experts in hazardous waste legislation, retired judges, economists, members of environmental organizations, legislators, and officers of corporations. The questionnaire included two cases of companies that made "products that are highly beneficial to people" and that had dumped hazardous waste into a landfill (following government standards but not using the best available technology) which now had to be cleaned up. The subjects had to apportion the costs between the companies and the government. In the deterrent case, "The more the company is made to pay, the more likely it is that the company and other companies will adopt the best available technology to avoid pollution in the future." In the perverse-deterrence case, "The more the company is made to pay, the more likely it is that the company and other companies, instead of changing their technology, will stop making the products that led to the waste." Only $15 \%$ of the subjects penalized the company more in the deterrent case than in the perverse case; $2 \%$ penalized more in the latter. The groups of subjects did not differ significantly in these proportions.

Baron (in press) found that when subjects are asked to judge how much compensation a victim deserves, they are influenced by whether the injury was caused by a human act or by nature, even if the injurer did not know of the injury and even if the victim did not know its cause. For example, in one case, a back injury resulted from tripping over a rock on a sidewalk. More compensation was provided when the rock rolled onto the sidewalk because of a construction crew working nearby than when it was washed there by rain.

Monetary compensation is theoretically inappropriate for some misfortunes, such as reproductive sterility, assuming that money will be less useful if one has fewer children. In fact, people do not purchase insurance against such events-except for medical insurance. But the tort system does provide compensation when the same events are caused by other people. Again, part of the desire to provide compensation in such cases could result from the frequent linkage of compensation with punishment. (It could also result from the fact that compensation does relieve suffering more effectively when the victim knows that it is compensation.)

The hypothesized psychological linkage of punishment and compensation might arise not only because these two functions are often linked in social institutions but also because of more general psychological principles. For example, equity theory predicts that when an injury occurs, people try to restore a preexisting balance (Walster, Walster, and Berscheid, 1978). People will want to hurt the injurer even if this hurt does not deter anyone, and they will tend to ignore the deterrent effect of their judgments. They will also want to compensate the victim in order to bring her closer to the level of the injurer, when an injurer can be found.

\section{Experiment 1}

The first experiment examines the factors that affect judgments of penalties and compensation when these two are separated by a new legal regime. Compensation was paid by the government, the penalties were paid to the government, and the two did not have to be equal. Penalties and compensation were provided by two separate panels. (A system something like this exists in New Zealand, and the U.S. worker's compensation 
laws contain some elements of it.) The amount of the penalty, then, could be determined without regard to the need for compensation, and the amount of compensation did not need to consider the cause of the injury.

We ask three main questions here. First, do subjects take into account the effect of penalties on future behavior in assessing penalties? Second do they take into account the cause of an injury-act vs. omission, people vs. nature, negligent vs. innocent behavior-in judging the amount of compensation when compensation is separated from penalties? Third, do subjects assess greater penalties when the injurer pays the victim directly than when the injurer pays the government and the government pays the victim? Several of these intuitions combined could support a system in which injurers pay victims larger amounts than are thought to be justified either in terms of appropriate penalties against injurers or in terms of compensation warranted by injuries (e.g., if they were caused naturally). Such judgments could be supported by the intuition that injurers must compensate those that they injure and by the intuition that cause is the relevant criterion for payment. Such a pattern could occur in real life, e.g., in the case of compensation of vaccine victims, which seems to provide, if anything, incentive only to stop making vaccines (Huber, 1987; Inglehart, 1987), while victims of identical but natural diseases go uncompensated.

\subsection{Method}

A questionnaire was completed by 28 members of Judicate, a group of arbitrators who are either retired judges or active judges, 16 environmental activists (from a list supplied by Clean Water Action), 9 members of the American Economic Association, 33 undergraduate students, and 6 law students -92 subjects in all. In describing the results, we shall also refer to a similar questionnaire, which we shall call the pre-questionnaire, answered by 29 students from the Philadelphia College of Pharmacy and Science and 5 from the University of Pennsylvania.

The questionnaire was introduced as follows:

This questionnaire presents some hypothetical cases that are related to current controversies in the law. We are giving this questionnaire to various groups, some of whom are familiar with the law and some of whom are not. When you answer it, please take the perspective of a citizen trying to judge what is simply best or right. You may, however, take into account whatever special knowledge you have. Please explain all of your answers.

Imagine that, a few years from now, the United States has a new law concerning medical misfortunes, such as injuries or diseases. According to this law, anyone who suffers such a misfortune can request compensation from the government. This compensation is in addition to medical expenses, which are paid out of universal medical insurance. If the misfortune might be caused by a medical product made by a company, the person who suffered the misfortune can file a complaint. For each complaint, two questions will be decided separately, each by a different panel: 
*One panel will decide whether the company will be fined, and, if so, how much. All fines go to the government, not the injured person. The panel that decides the fines considers only the justice of imposing the fines. It ignores the needs of the government for money, and it ignores how the money will be spent.

*The second panel will decide how much the injured person will be compensated. If any compensation is paid, the government pays it, not the company. This panel takes into account only the situation of the injured person. It ignores the cost to the government, and it ignores the responsibility of the government, if any, for causing or preventing the misfortune.

Compensation can be provided even if the company pays nothing, and the company can be fined even if no compensation is provided. The government does not have to break even in the long run.

The panel that decides on compensation to the victim does not know how much the company has been fined, if anything, and the panel that decides on fines does not know how much compensation has been given to the injured person.

If the misfortune was not caused by a product, the person who suffered the misfortune can still ask for compensation. Only the second panel will hear the case.

Two cases were presented, with several "versions" after each case. Here is the first case and its first version:

A woman who took a new birth control pill has become sterile as a result of taking the pill, and she brings a complaint against the ABC Company, which produced the pill. The woman has one child already, and she is upset and angry because she cannot have another. The pills had been tested on several thousand women, all of whom had had a previous pregnancy and intended to have another. The effect of the pills on the fertility of the women could therefore be observed. Other pills had been tested in the same way. The pills produced various side effects, but they were found to be safer than all pills made by other companies. A package insert that came with the pills warned truthfully about several side effects, but it did not mention sterility because no cases of sterility had been observed among the women who took the pill during testing.

Version $A$. The pill was profitable and the ABC Company knew that it would be. It was, after all, safer than other pills. The company knew how to make an even safer pill but had decided against producing it because the company was not sure that the safer pill would be profitable. If the company were to stop making the pill that the women took, it would make the safer pill.

The subject was then asked: "Should the company pay anything to the government in this case? Why or why not?" and "Should the woman be compensated by the government? Why or why not?"

Here is the second case: 
A type of flu kills many young infants. A pharmaceutical company discovers a way to make vaccines that will prevent the flu. The vaccines will prevent the flu completely, but they have side effects that will kill some infants, even if the vaccines are made to specification. If all children were vaccinated, the number of children who would die from the vaccines would be a tenth of those who would die from the flu if no children were vaccinated. No other company knows how to make any vaccines against this flu.

Version $A$. A child dies from the vaccine, and the parents bring a complaint against the company. The vaccine used was made to specification, and the package insert warned about the possibility of death.

The company had considered making a safer vaccine but had decided against it because it was not sure that the safer vaccine would be profitable. The vaccine in question was profitable and the company knew that it would be. If the company were to stop making this vaccine, it would produce the safer vaccine.

Again, the subjects was asked about both compensation and penalties. In subsequent versions of both cases, the subject was asked whether penalties and compensation should be more or less than in version $\mathrm{A}$, or than in some other version. The versions differed in whether the company would stop making the product in question rather than try to improve it (B); the injury occurred because the company decided not to make the product (C); the penalty was secret and the company insured, so that the penalty had no deterrent effect (D); the same, but the company paid the victim directly (E); the injury was caused by natural causes (with no company involved) (F); the company was negligent in making the product (G, case 2 only). More details will be described with the results.

\subsection{Results}

In general, the groups of subjects did not differ significantly in their answers, so we shall note group differences only when we found them. Of the 92 subjects, 52 wanted to penalize the company in version A, case 1 , and 70 in version A, case 2 . Seventy-five wanted to penalize the company in at least one case. Sixty-one wanted to compensate the victim in version $A$, case 1,62 in case 2 , and 74 in at least one case. We describe the main results according to a set of questions.

Do people see deterrence or incentive-future consequences - as a reason for increasing or decreasing penalties? One test for this was the comparison of version $\mathrm{A}$, in which the penalty would bring about improved behavior (making a safer product), with version B (perverse incentive), in which subjects were told (in case 2, for example), "If the company were to stop making this vaccine, it would not make any vaccine for this flu, so there would be no vaccine available." If people said that the company should be punished less in the second question, then they were sensitive to the deterrent effects of the penalties. Out of 74 respondents who would fine the company in version A of case 1 or 2 and who 
answered this question, 23 did think that the company should be punished less in version B in at least one of the two scenarios, and 3 thought the company should be punished more. The remaining 48 respondents were not sensitive to the incentive issue in these items.

A second test for incentive was version $\mathrm{D}$ (no deterrence), in which differed from version $\mathrm{A}$ in that "the amount of payment made by the company was absolutely secretknown only to the government and to a few trustworthy officials of the company, who were retiring; and the company was insured by a long-term policy that would cover all liability costs in full, at a premium set for the industry as a whole and constant for all companies. These two facts together mean that decisions about payment to the government could have no effect on future decisions by this company or other companies about which vaccines to produce." Out of 72 respondents who penalized the company in version A of case 1 or 2 and who answered this question, 17 did penalize the company less in this question, and 7 penalized the company more. Again, 48 respondents were not sensitive to incentive effects here. Answers to this question were correlated in the expected direction with the answers to the question described in the last paragraph (Kendall's $\tau=.27, p<.025$ ), which indicates that these questions measure a general attitude toward incentive. Results from the comparable question in the pre-questionnaire showed an even greater neglect of deterrence: only one subject in each version (out of 22 in case 1 and 25 in case 2) compensated less here than in version A.

Does compensation depend on the cause of the injury? In each case, the particular injury (sterility, death of a child) was held constant across the questions. Differences in the need for penalties could not serve as a reason for differences in compensation, because these two decisions were independent. We examined three different factors that could affect compensation in the absence of differences in the victim's need for compensation: whether the injury was caused by an act or omission (version $\mathrm{C}$ vs. A); whether it was caused by nature or a company (version F vs. E or A); and whether the company that caused it was negligent (version $G$ vs. A). In the negligence case, the negligence itself did not lead to the injury.

In version $\mathrm{C}$ (omission), the injury was caused by a company's failure to produce the product; either the victim used a more risky product (case 1) or died from the flu (case 2). Out of the 64 respondents who compensated the victim in at least one case and who answered this question, 20 provided less compensation (in at least one case) when the harm was caused by an omission and 1 provided more compensation. The effect was significant in both cases. (Significant results were also found in the pre-questionnaire.) (Two thirds of the subjects did not penalize the company for its omission in version $\mathrm{C}$ of either case. We cannot interpret this result because we did not hold constant such factors as the company's intention.)

Version F of case $1 \mathrm{read}$, "Suppose that the woman became sterile from natural causes. She took no birth control pills. (Remember, the government can compensate people for misfortunes such as sterility regardless of their cause.)" For case 2, it read (with the same reminder), "Suppose that there was no vaccine and the child died from the flu." Out of 69 respondents who provided compensation in at least one case and who 
answered version $F, 40$ provided less compensation for natural injuries than those caused by the company (in at least one case), 29 provided equal compensation in both cases, and none provided more compensation for natural injuries. Again, similarly strong results were found in the pre-questionnaire.

Version G read, "The company is negligent in monitoring the production of the vaccine. The vaccine given to the child who died was made to specification, however, and it would not have been withheld if the company had been more careful." Out of 76 respondents who provided compensation in at least one case and who answered version $G, 10$ provided more compensation when the company was negligent and 1 provided less compensation. Groups differed ( $p=.001$ by chi-square), with judges, economists, and activists providing equal compensation regardless of the company's negligence. In the pre-questionnaire, compensation was also increased when the company "committed serious violations of worker safety rules . . . to increase its profits" (13 increases, no decreases, out of 21 subjects in case 1; 6 increases, no decreases, out of 12 in case 2).

It is possible that these results concerning compensation could be explained by subjects' beliefs about the emotions of those who were compensated. We doubt this for two reasons: no subject mentioned such emotions as a justification of compensation; and previous results (Baron, in press; Ritov and Baron, 1992) ruled them out as explanations of similar phenomena.

Does direct compensation have special status? In our cases, penalties and compensation were determined separately and did not have to be equal. Typically, however, injurers pay victims directly. We thought that people might have a basic intuition about the need to "undo" a harm and that this intuition would lead to greater payment when the compensation was paid directly. In other words, people might see the provision of compensation as more than just the assessment of a penalty and the provision of compensation. We tested this by asking how much compensation should be provided to the victim if the injurer pays directly (version $\mathrm{E}$ ), in the context of version $\mathrm{D}$, in which the penalty was secret and the injurer was insured.

Out of 83 respondents who answered the relevant question at least once, 24 provided more compensation when the company paid the victim directly and 4 provided less compensation. Moreover, 44 of the 83 respondents who answered the relevant questions provided more compensation here than when the injury was naturally caused. (Groups differed here, $p=.002$, with students most inclined to make this distinction and economists least inclined to make it.) Out of 79 subjects who answered all the relevant questions, 22 showed both of these effects together and only one showed the reverse effects (more compensation from nature and less compensation with direct payment, $p<.001$ ). (The pre-questionnaire did not permit this analysis.)

This pattern of responses cannot be justified in terms of compensation or incentive. The need for compensation does not change as a function of the direct payment. Incentive is absent because of the insurance the the secrecy. We conclude, then, that a substantial proportion of respondents are inclined to ask injurers to pay more and victims to receive more when the payment is direct, as it is in most cases in the real world. Such a 
pattern of responding would lead to excessive use of the tort system, which makes direct payments, compared to what could be justified by the functions of compensation and deterrence.

Our general conclusion is that intuitions about compensation and penalties are based on other considerations than the consequences for fulfilling needs or deterring future harm. Although some respondents, in their answers and their explanations, did consider consequences in some detail, many others did not.

\section{Experiment 2}

Experiment 1 demonstrated that many people do not take incentive and deterrence effects into account in decisions about punishment. This is a surprising result, given that many writers hold that these effects are the sole justification of punishment. Experiment 2 checked this result by presenting modified forms of the questionnaire used in experiment 1 .

In addition, we presented an argument about deterrence and incentive. After reading the argument, subjects responded to the same cases again. Of particular interest is whether subjects said that they had thought of the argument before. We ask, then, whether failure to use the deterrence principle is the result of not thinking of it, thinking of it and rejecting it, or both. This question is relevant if we want to increase the use of this principle in the legal system or elsewhere. If people simply do not think of it, then we simply need to teach it to them. If they reject it, then we need to engage them in a more thorough dialogue.

\subsection{Method}

Two different modified forms were used. Form I contained essentially the basic cases presented in experiment 1 , using the version of each case in which making the company pay would lead to withdrawal from the market, and the version in which nobody would know about the amount of payment (so that it could set no precedent). Form II eliminated this secret version but kept the version in which payment would make the company withdraw from the market. It thus contained only version $A$, in which the company would make the safer product, and version $B$, in which the company would stop making the product altogether. In addition, form II eliminated the distinction between compensation and penalty. The situation was therefore just as it is in the present U.S. tort system. Subjects were asked whether the company should pay the plaintiff(s). Twenty-eight students did form I, and 23 did form II.

In both forms, the subjects were given an argument explaining the deterrence justification of penalties and were asked to answer the questions again. The argument used in form II concluded, "In sum, when a company is penalized, its behavior is deterred, and that behavior can be better or worse than the alternative to it. If the behavior is worse 
than the alternative, then we have reason to penalize the company. If the behavior deterred is better than the alternative, then we have reason not to penalize the company. Of course, these deterrent effects are not the only effects of lawsuits. But, if you did not think about these effects before, we want to see how thinking about them now will affect your judgments." The argument in form I was similar.

After answering the original cases again, in both forms, the subject was asked two final questions: "If you have not already done so, please explain how the argument affected your answers, or why it did not affect your answers." "If the argument did affect your answers, had you ever thought of it before?"

\subsection{Results}

The results for compensation in form I were similar to those of experiment 1 and are therefore not presented. (We asked about compensation mainly to ensure that subjects understood that compensation and penalties could differ.)

In form I, the incentive argument should lead subjects to penalize the company more in version $\mathrm{A}$ (company will try harder if penalized) than in version $\mathrm{B}$ (company will stop making product) or version $\mathrm{C}$ (secret). In general, the argument had little effect on these judgments. The top part of table 1 shows the numbers of subjects who did or did not take incentive into account in their judgments, before and after reading the argument. Subjects who did not take incentive into account either did not penalize the company in either version or penalized the company in both versions.

In response to the final question about their response to the incentive argument, of the 21 subjects whose answers could be clearly scored (either from their answers to these questions or earlier ones), 5 had thought of the argument before and accepted it, 5 had not thought of it before and accepted it, 6 had thought of it before and rejected it (or did not apply it to their judgments), and 5 had not thought of it before and rejected it. Some rejections were quite explicit, e.g., "Either the company is to blame or it isn't."

In form II, as shown in the bottom part of table 1, most judgments were again unaffected by the argument. In the answers to the final questions about their response to the argument, only 14 subjects answered both questions clearly. Of these, 2 had thought of the argument and accepted it, 3 had not thought of it and accepted it, 7 had thought of it and did not accept it, and 2 had not thought of it and did not accept it. Again, some rejections were explicit, e.g., "To say that she should not be paid for her suffering because that would deter progress is using the ends to justify the means. There are other ways to achieve progress besides causing some to suffer." In other cases, rejections were more pragmatic, e.g., "If the pill is safer than the rest of the market, it is negative that it will stop, but still there are other birth control alternatives to the public, so it won't be such a loss to society." (Note, however, that the other alternatives were worse.)

In sum, these results indicate a mixture of four kinds of subjects: those who have not thought of the argument and accept it, those who have not thought of it and reject it, those who have thought of it and accept it, and those who have thought of it and reject it. 
Table 1. Number of subjects (and percent of those answering) in experiment 2 who did ("yes") or did not ("no") take incentive into account in each comparison, before and after reading the argument defending the principle of incentive

Form I

\begin{tabular}{|c|c|c|c|c|c|}
\hline \multirow{3}{*}{$\frac{\text { Before }}{\text { Yes }}$} & \multirow{3}{*}{$\frac{\text { After }}{\text { Yes }}$} & \multicolumn{2}{|c|}{ Birth-control pill } & \multicolumn{2}{|c|}{ Vaccine } \\
\hline & & IA vs. IB & lA vs. $1 \mathrm{C}$ & $2 \mathrm{~A}$ vs. $2 \mathrm{~B}$ & $2 \mathrm{~A}$ vs. $2 \mathrm{C}$ \\
\hline & & $(14 \%)$ & $(4 \%)$ & $6 \quad(21 \%)$ & $4 \quad(15 \%)$ \\
\hline Yes & No & $(0 \%)$ & $(0 \%)$ & $(14 \%)$ & $1 \quad(4 \%)$ \\
\hline No & Yes & $5 \quad(18 \%)$ & $5 \quad(19 \%)$ & $(11 \%)$ & $(7 \%)$ \\
\hline No & No & $19 \quad(68 \%)$ & $20 \quad(77 \%)$ & $15 \quad(54 \%)$ & $20 \quad(74 \%)$ \\
\hline
\end{tabular}

Form II

\begin{tabular}{|c|c|c|c|}
\hline \multirow[b]{2}{*}{ Before } & \multirow[b]{2}{*}{ After } & Birth-control pill & Vaccine \\
\hline & & $1 \mathrm{~A}$ vs. $1 \mathrm{~B}$ & $2 \mathrm{~A}$ vs. $2 \mathrm{~B}$ \\
\hline Yes & Yes & $4 \quad(19 \%)$ & $4 \quad(19 \%)$ \\
\hline Yes & No & $0 \quad(0 \%)$ & $0 \quad(0 \%)$ \\
\hline No & Yes & $2(10 \%)$ & $3(14 \%)$ \\
\hline No & No & $15 \quad(71 \%)$ & $14 \quad(67 \%)$ \\
\hline
\end{tabular}

Case 1 is the birth-control pill; case 2 is the vaccine. In version $\mathrm{A}$, the company will improve if fined; in version $\mathrm{B}$, the company will stop; in version $\mathrm{C}$, the penalty is secret.

The relative proportions of such subjects will surely depend on the type of case and the population sampled, but it is clear that all four types can be found in substantial numbers. Perhaps the somewhat greater resistance to the incentive argument in form II than in form I results from the lack of an alternative means of providing compensation. (We must bear in mind, however, the resistance of subjects in experiment 1 to compensating people for acts of nature.)

\section{Experiment 3}

In experiment 3, we tried a different approach to finding out whether people had thought of the incentive argument and whether they found it relevant to liability judgments in the context of cases in which the injurer pays the plaintiff. We presented subjects with version $\mathrm{A}$ (the company would improve if fined) and version $\mathrm{B}$ (the company would stop making the product if fined) and simply asked them if the distinction was relevant to determining the fine. We also asked why someone else might think the distinction was relevant in case they did not think it was. 


\subsection{Method}

The same two cases (birth-control pill and vaccine) were used as in experiment 2, form II. Again, we used two forms. The critical questions for form I (case 1) were as follows:

Consider the following two versions:

Version $A$. If the company were to change its behavior in any way as a result of losing the suit, it would make the safer pill.

Version $B$. If the company were to change its behavior in any way as a result of losing the suit, it would cease making pills altogether. Also, no other companies would try to make better pills.

1. Should the difference between Version A and Version B matter in determining whether the company has to pay damages, or (if it does) how much it has to pay? Why or why not?

2. If you think the difference doesn't matter, why might someone think that it does matter?

The two versions for the vaccine case were analogous. In version B, "the company ... would not make any vaccine for this flu, so there would be no vaccine available. Also, no other companies would try to make vaccine for this flu."

In form II, the versions for the pill case were as follows:

Version $A$. If the company lost the suit and had to pay, it and other companies would probably spend more on research to try to make safer pills.

Version $B$. If the company lost the suit and had to pay, it and other companies would be less likely to keep this pill and similar pills on the market.

The vaccine versions were analogous. The changes in form II were designed to prevent the interpretation of the versions as a threat and to call attention to the precedent-setting effect for other companies.

Twenty-eight students did form I (of which 5 were dropped for misunderstanding or otherwise not answering the questions), and 59 did form II (of which 10 were dropped for the same reasons). The most common misunderstanding was saying which outcome was better rather than whether the expected outcome should affect the fine.

\subsection{Results}

Table 2 shows the results for both forms, for subjects whose answers could be clearly categorized. Once again, all possible responses are represented. Some subjects applied the incentive principle to their judgment; others knew it (when asked how others might respond) but did not apply it to their own judgments; and still others showed no evidence of knowing it. In form I, it seemed somewhat easier to think of the incentive argument in 
the vaccine case, perhaps because the effect on death rates was clear here. Still, although many subjects thought of the argument, most who thought of it rejected it.

Examples of subjects who accepted and applied the incentive argument are as follows: "Of course [the difference matters], because if the result of being sued impacts so heavily not only on the parties in this case, but on the whole industry (and its consumers), then this must be taken into account. Individual vs. social justice." "... I would not hold [the company] responsible, but if I knew they could and would produce a safer vaccine if penalized, I would have them lose the suit for the sake of infants on their vaccine in the future." "It would be a pretty sorry version of justice if 10 times [the number of] infants were to die just so that one family would be compensated for their loss." "If losing the case would result in the company's leaving the marketplace, I feel that it would not be in the interest of society to find them negligent. More babies would die without the vaccine..."

Those who rejected the incentive argument generally felt that fines should be based on the facts of the case, what happened in the past, or the need for compensation, not on effects in the future. For example: "... we are dealing with solely what happened to the woman." "A woman has been hurt and she must be rightly compensated." "The damage was already done to that woman." "It should have to pay damages if it was at fault." "Company ABC should pay for its previous actions on account of those actions." "The point of this case has to do with personal injury to the woman, and the outcome of the case is to make the injured party whole again or compensate for her injury. ..."

Of particular interest are some subjects who explicitly rejected future consequences as a basis for legal decisions, for example: "The liability issue should be decided based only on the facts of the particular case. The possible consequences of the company losing the suit should not in any way have a bearing on the particular woman's case." "The legal consequences of a past action on decision should not be judged based on its ramifications for future actions/decisions." "The question is whether the company did any wrongdoing against the woman. The decision on whether they pay has nothing to do with their future actions." ". . . long term policy decisions of the company are not the victim's concern."

Table 2. Number of subjects (and percent of those answering clearly) in experiment 3 who applied the incentive principle to their judgment, knew it (when asked how others might respond) but did not apply it to their own judgments, or showed no evidence of knowing it.

\begin{tabular}{|c|c|c|c|c|c|c|c|c|}
\hline \multirow[b]{3}{*}{ Applied to judgment } & \multicolumn{4}{|c|}{ Form I } & \multicolumn{4}{|c|}{ Form II } \\
\hline & \multicolumn{2}{|c|}{ Case 1} & \multicolumn{2}{|c|}{ Case 2} & \multicolumn{2}{|c|}{ Case 1} & \multicolumn{2}{|c|}{ Case 2} \\
\hline & 5 & $(23 \%)$ & 4 & $(24 \%)$ & 5 & $(17 \%)$ & 6 & $(24 \%)$ \\
\hline Knew but rejected & 5 & $(23 \%)$ & 10 & $(59 \%)$ & 9 & $(30 \%)$ & 7 & $(28 \%)$ \\
\hline Didn't know & 12 & $(55 \%)$ & 3 & $(18 \%)$ & 16 & $(53 \%)$ & 12 & $(48 \%)$ \\
\hline
\end{tabular}

Case 1 is the birth-control pill; case 2 is the vaccine. In version A, the company will improve if fined; in version $\mathrm{B}$, the company will stop. 
"The amount and the decision to pay damages depends on the company's past performance, not on what it may or may not do in the future." "The court's decision may cause an increase in research, but that doesn't make a difference now."

In form I, 3 subjects did in fact perceive the description of the possible outcomes as a threat, for example: "The company's reaction to losing the suit should in no way be considered in the decision making process. It it was any industry ... could circumvent the law by threatening to later withhold its services."

Several subjects -8 in form I but only 3 in form 2-took the difference between versions into account in exactly the opposite way from that dictated by the incentive principle. In particular, they argued for leniency in version A (when the company would try harder if it were fined) on the grounds that the company was more deserving. The reduction of this idea in form 2 might have resulted from the emphasis on the effect on other companies. Examples are: "Some might think that it does matter because B shows the company to be extremely selfish/immoral. Many might feel that they should have to pay more for their callousness." ". . . ceasing to make pills altogether means [the company] has committed a crime...."

Another type of nonincentive response to the question of why someone might think that the difference mattered was that it mattered to the profits of companies, for example: "It would matter to someone else, I think, because they would consider ... the effect this decision will have on drug manufacturing companies." "It could matter if you were president of the company because it would decrease profits." "Version A forces other companies to spend money on research that might exceed the losses [sic] of the company in question. However, in Version B, the other companies are almost given free business advice."

\section{Discussion}

Our results suggest that intuitions about punishment and compensation, in the context of tort law, are variable from person to person and are not typically consequentialist. Many subjects regard penalties as an automatic consequence of causing injury (perhaps only with some negligence), regardless of the incentive effects of assessing the penalties. Many subjects have not learned the deterrent rationale to the point where they can recall it and bring it to bear on cases. Others have learned it but still reject it. Some who are presented with the rationale for what seems to them to be the first time accept it, but others reject it because it conflicts with their intuition.

Likewise, many people assign compensation not in terms of the injury but rather in terms of setting the balance right between the injurer, if any, and the victim. Victims thus can receive less compensation for injuries caused by omissions or by nature than for injuries caused by acts.

These nonconsequentialist attitudes, taken together, constitute a kind of support for a system in which people are compensated for injuries caused by acts but not for other injuries. Compensation is provided even when the incentive effects of providing it are 
harmful in the long run, as in the case of vaccines (clearly) or (only a little less clearly) medical specialties such as obstetrics, which are losing practitioners because of frequent lawsuits.

Presumably the nonconsequentialist intuitions we have found are not limited to the U.S. Certainly our account of how they arise-in terms of overgeneralization based on incomplete understanding of purposes-is not specific to any particular culture. If these intuitions are to explain the bad outcomes of the legal system, why are these outcomes found more often in the U.S. than in other countries, as such outcomes seem to be (Huber and Litan, 1991)? Schwartz (1991) suggests that the U.S. legal system contains several jointly unique features that encourage frequent litigation, thus giving these intuitions more opportunity to affect outcomes. These features include the widespread use of jury trials for product liability and malpractice cases, the fact that losing plaintiffs are not liable for the defendant's legal expenses, and the use of contingent fee arrangements in which the plaintiff's lawyer is not paid if the plaintiff loses.

Our results create a puzzle for positive economic theories of law, particularly that of Landes and Posner (1987). If the system can be understood in terms of the consequentialist rationale, as they claim it can, what human judgments maintain it? Note that our main findings held even for judges, and most of our other subjects are potential jury members. Perhaps the present system is not so close to be the "best of all possible consequentialist worlds," as Landes and Posner would suggest. The system might yield better outcomes if its consequentialist rational were more widely understood and applied.

Conceivably, such understanding would lead to less use of the tort system, which cannot compensate victims of nature and which can discourage useful activities, and more emphasis on insurance (including social insurance) and regulation. Schools can play a role in teaching citizens various justifications of legal principles, including the consequentialist ones, as part of the social studies curriculum and elsewhere.

\section{References}

Baron, Jonathan. (1991). "Harmful Heuristics and the Improvement of Thinking." In D. Kuhn (ed.), Developmental Perspectives on Teaching and Leaming Thinking Skills. Basel: Karger.

Baron, Jonathan, (In press). "Heuristics and Biases in Equity Judgments: A Utilitarian Approach." In B. A. Mellers and J. Baron (eds.), Psychological Perspectives on Justice. New York: Cambridge University Press.

Baron, Jonathan, Rajeeve Gowda, and Howard Kunreuther. (1993). "Attitudes toward Managing Hazardous Waste: What Should be Cleaned Up and Who Should Pay for It?" Risk Analysis 13, 183-192.

Baron, Jonathan and John C. Hershey, (1988). "Outcome Bias in Decision Evaluation," Joumal of Personality and Social Psychology, 54, 569-579.

Brown, John P. (1973). "Toward an Economic Theory of Liability," Joumal of Legal Studies, 2, 323-349.

Calabresi, Guido. (1970). The Costs of Accidents: A Legal and Economic Analysis. New Haven: Yale University Press.

Calfee, John E., and Paul H. Rubin. (In press). "Some Implications of Damage Payments for Nonpecuniary Losses," Journal of Legal Studies. 
David, A.B. (1986). "DTP: Drug Manufacturers' Liability in Vaccine-Related Injuries," Joumal of Products Liability 94, 361-405.

Djerassi, Carl. (1989). "The Bitter Pill," Science 245, 356-361.

Fincham, Frank D. and Joseph M. Jaspars. (1980). "Attribution of Responsibility: From Man the Scientist to Man as Lawyer," Advances in Experimental Social Psychology 13, 81-138.

Friedman, David. (1982). "What is 'fair compensation' for death or injury?" Intennational Review of Law and Economics 2, 81-93.

Hinman, A.R . (1986). "DTP Vaccine Litigation," American Joumal of Diseases of Children 140, 528-530.

Hofmann, M. A. (1988). "No-fault System to Compensate Vaccine Injuries," Business Insurance 22 (5), 3, 24-25.

Huber, Peter W. (1988). Liability: The Legal Revolution and Its Consequences. New York: Basic Books.

Huber, Peter W. (1991). Galileo's Revenge: Junk Science in the Courtroom. New York: Basic Books.

Huber, Peter W. and Robert E. Litan (eds.). (1991). The Liability Maze: The Impact of Liability Law on Safery and Innovation. Washington: Brookings Institution.

Inglehart, John K. (1987). "Compensating Children with Vaccine-Related Injuries," New England Joumal of Medicine 316, 1283-1288.

Landes, William M. and Richard A. Posner. (1987). The Economic Structure of Tor Law. Cambridge, MA: Harvard University Press.

Mastroianni, Luigi, Jr., Peter J. Donaldson, and Thomas T. Kane. (1990). Developing New Contraceptives: Obstacles and oppontunities. Washington: National Academy Press.

Ritov, Ilana and Jonathan Baron. (1990). "Reluctance to Vaccinate: Omission Bias and Ambiguity," Joumal of Behavioral Decision Making 3, 263-277.

Ritov, Ilana and Jonathan Baron. (1992). "Judgments of Compensation for Misfortune: The Role of. Expectation," manuscript, Department of Psychology, University of Pennsylvania, Philadelphia, PA.

Schwartz, Alan. (1988). "Proposals for Products Liability Reform: A Theoretical Synthesis," Yale Law Joumal 97, 353-419.

Schwartz, Gary T. (1991). "Product Liability and Medical Malpractice in Comparative Context." In P. W. Huber and R. E. Litan (eds.), The Liability Maze: The Impact of Liability Law on Safety and Innovation. Washington: Brookings Institution, pp. 28-80.

Shavell, Steven. (1987). Economic Analysis of Accident Law. Cambridge, MA: Harvard University Press.

Spranca, Mark, Elisa Minsk, and Jonathan Baron. (1991). "Omission and Commission in Judgment and Choice," Journal of Experimental Social Psychology, 27, 76-105.

Viscusi, W. Kip and Michael J. Moore. (In press). "Product Liability: Research and Development, and Innovation," Joumal of Political Economy.

Walster, Elaine, G. W. Walster and Ellen Berscheid (1978). Equity: Theory and Research. Boston: Allyn \& Bacon. 
Copyright of Journal of Risk \& Uncertainty is the property of Kluwer Academic Publishing / Business and its content may not be copied or emailed to multiple sites or posted to a listserv without the copyright holder's express written permission. However, users may print, download, or email articles for individual use. 